\title{
Combining Wind and Pumped Hydro Energy Storage for Renewable Energy Generation in Ireland
}

\author{
Alice Coburn, ${ }^{1}$ Eilín Walsh, ${ }^{1}$ Patrick J. Solan, ${ }^{1}$ and Kevin P. McDonnell ${ }^{1,2}$ \\ ${ }^{1}$ School of Biosystems Engineering, University College Dublin, Belfield, Dublin 4, Ireland \\ ${ }^{2}$ School of Agriculture and Food Science, University College Dublin, Belfield, Dublin 4, Ireland \\ Correspondence should be addressed to Eilín Walsh; eilin.walsh@ucd.ie
}

Received 17 June 2014; Accepted 5 August 2014; Published 21 August 2014

Academic Editor: Michele Messina

Copyright (C) 2014 Alice Coburn et al. This is an open access article distributed under the Creative Commons Attribution License, which permits unrestricted use, distribution, and reproduction in any medium, provided the original work is properly cited.

\begin{abstract}
Ireland has one of the highest wind energy potentials in Europe. The intermittent nature of wind makes this renewable resource impractical as a sole source of energy. Combining wind energy with pumped hydro energy storage (PHES) can overcome this intermittency, consuming energy during low-demand periods and supplying energy for periods of high demand. Currently Ireland has a number of hydroelectric power plants and wind farms of various scales in operation. A feasibility study was conducted to investigate the potential of securing a reliable source of renewable energy by increasing the penetration of hydroelectric power by means of combined wind-PHES developments. The greatest wind potential is experienced along the western coast of Ireland and a number of sites were identified here which satisfied a minimum mean wind speed criterion of $10.5 \mathrm{~ms}^{-1}$. Each site was then further evaluated according to topographical requirements for PHES. All but two of the identified sites are immediately unsuitable due to the presence of areas protected under European legislation; this highlights the nonenergy related obstacles in the path of renewable energy generation in Ireland and suggests that a compromise should be researched which could facilitate both renewable energy generation and species and habitat protection in Europe.
\end{abstract}

\section{Introduction}

The negative implications of fossil fuel-based energy systems are well known and efforts to secure an alternative, renewable, and sustainable source of energy have increased in recent decades. Which alternative form of energy is the most suitable for a specified location depends primarily on the location itself: sunlight exposure, wind potential, agrosuitability for biomass cultivation, and so forth each determine the applicability of a particular energy source to a particular location.

Ireland is committed to an overall target of $16 \%$ renewable energy penetration for electricity, heating, and transport by 2020 under the EU Renewable Energy Directive (2009/28/EC). Located on the eastern fringe of the Atlantic Ocean, Ireland experiences some of the highest wind energy potential in Europe (Figure 1). Wind energy accounted for $7.5 \%$ of the total electricity generation in Ireland in 2012 [1]. One of the most significant characteristics of wind energy and one of the main obstacles to achieving the renewable energy targets set out by Directive 2009/28/EC is its intermittency.
This is highlighted in the $8.4 \%$ reduction of the contribution of wind energy to electricity generation in Ireland due to a lower wind potential compared to the previous year [1]. At times of fine weather, when wind speed is insufficient to turn wind turbines, electricity production drops significantly and can cease completely [2]. Furthermore, wind energy cannot be "dialled up and down" to respond to variations in energy demands, whether they are diurnal, seasonal, or annual. The intermittency and unpredictability of wind energy generation can be overcome by combining with an energy storage technology to overcome this asynchrony in electricity production supply and demand [3] and provide a more consistent and reliable supply of electrical energy.

Ireland currently has a number of operational hydroelectric power plants of varying capacities which provided just under $3.5 \%$ of the total electricity generated in 2012 [1]. Only one of these plants, Turlough Hill which is located in the east of the country, operates as a pumped storage facility. Turlough Hill can generate up to $292 \mathrm{MW}$ of electricity during periods of peak demand by releasing water from an upper reservoir 


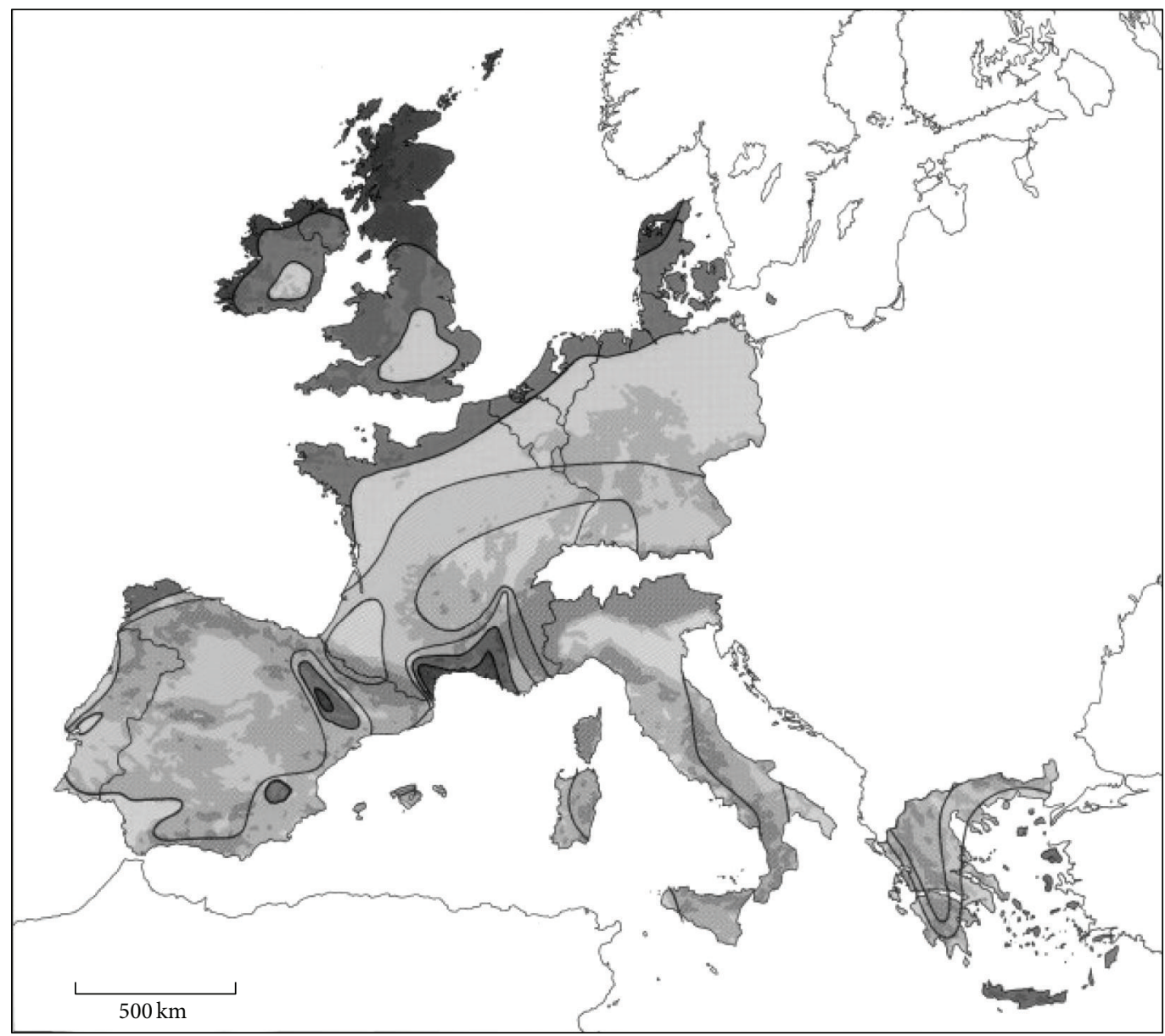

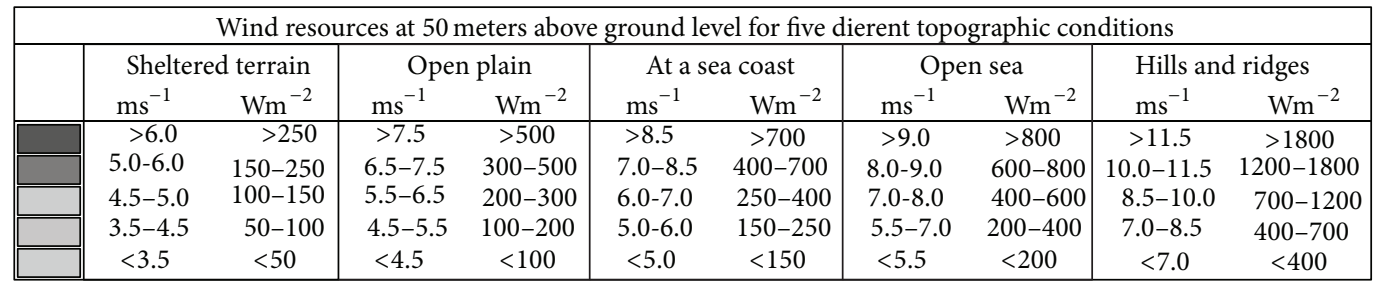

FIGURE 1: Wind resources in Europe (50 m above ground level, after Risø National Laboratory [4]).

to a lower reservoir, passing through turbines to generate electricity [5]. Combining wind energy with pumped hydro energy storage (PHES) can overcome the intermittency in supply associated with wind energy [3]: during periods of low demand the electricity produced by wind turbines can be used to pump water from a lower reservoir to an upper reservoir where the energy is stored as water. When wind speeds change and the rate of electricity generation from wind falls or when consumer demand rises, water stored in the upper reservoir is released to the lower reservoir, converting potential energy into kinetic energy and generating electricity $[6,7]$.

Ireland has the technical expertise to generate electricity using pumped hydro energy storage and has a wind energy potential too good to be overlooked, yet it depends heavily on imported fossil fuels for electricity generation. This research study therefore investigated the feasibility of developing combined wind-PHES facilities to secure a renewable energy resource for Ireland to meet targets set by the European Union relating to renewable energy generation. A variety of sites were selected based on a number of preliminary topographical criteria and their suitability for such an energy development was evaluated. Care was taken to consider all aspects of each selected site, including whether the sites are currently protected under European legislation relating to habitat and species protection (EU Habitats Directive, 94/43/EEC and EU Birds Directive, 79/409/EEC, resp.).

\section{Method and Materials}

As is evident from Figure 1, the greatest wind energy potential in Ireland is experienced along the western and northwestern coastlines due to exposure to Atlantic weather systems. Site selection for potential combined wind-PHES 
developments is therefore focussed primarily in these areas. Optimal wind energy generation in these locations was facilitated by selecting a turbine hub height of $100 \mathrm{~m}$ : Engström et al. [8] investigated wind energy generation using $3 \mathrm{MW}$ wind turbines with hub heights of between $80 \mathrm{~m}$ and $175 \mathrm{~m}$ and reported an average wind speed of $6.2 \mathrm{~ms}^{-1}$ at a hub height of $100 \mathrm{~m}$ which generated 6,328 MWh annually. At $100 \mathrm{~m}$ height the wind speed along the west coast of Ireland ranges between 10.00 and $11.75 \mathrm{~ms}^{-1}$ [9], substantially higher than those recorded by Engström et al. [8] and therefore potentially offering a higher rate of electricity generation. A combined minimum infrastructural requirement of $100 \mathrm{~m}$ hub height $10.50 \mathrm{~ms}^{-1}$ minimum wind speed was selected in this study to maximise the electricity generation potential.

Conditional criteria for PHES include the presence of a high head, favourable topography, good geotechnical conditions, access to the electricity transmission networks, and water availability [10]. Geological impermeability is a particularly important criterion when planning PHES as it will directly influence the storage of water in a reservoir. In particular, as a number of potential sites in Ireland are located along the coastline, the Atlantic Ocean was modelled as the lower reservoir and in these cases geological impermeability is essential to avoid contamination of a freshwater environment when marine water is pumped into an upper reservoir. Although sites which use freshwater in both upper and lower reservoirs do not experience the same problem of marine contamination, the same geological criteria were considered for marine and freshwater sites investigated in this study.

To prevent leakages and contamination, a reservoir for PHES should be underlain by bedrock which is impermeable and which has minimal fissures. The most suitable rock type for marine-based PHES reservoirs which occurs in Ireland is schist, a metamorphic sedimentary rock [11]; Figure 2 illustrates the occurrence of schist in locations in the west and northwest of the country. There is no minimum required head height for PHES: a facility in Portugal currently operates with a head of just $26 \mathrm{~m}$; however a SETIS expert panel has suggested a minimum head of between 50 and $200 \mathrm{~m}$ for national projects [12]. In this study the higher end of this recommended head height range was selected to optimise the electricity generation potential from such a development: $200 \mathrm{~m}$ was chosen as the required head height. Ireland's topography consists of both lowlands and mountainous regions and many of the latter occur in the west of the country. This topography may contribute to potential windPHES facilities sited along the western coast of Ireland.

A number of sites were identified using the Ordnance Survey of Ireland (OSI) Map Viewer (Ordnance Survey of Ireland Map Viewer, available at http://www.osi.ie/) interactive tool and examined to determine their suitability for combined wind-PHES electricity generation in Ireland. These sites were identified using minimum criteria including mean wind speed and site elevation. The potential suitability of the identified sites was then examined according to the underlying bedrock type; proximity to the transmission

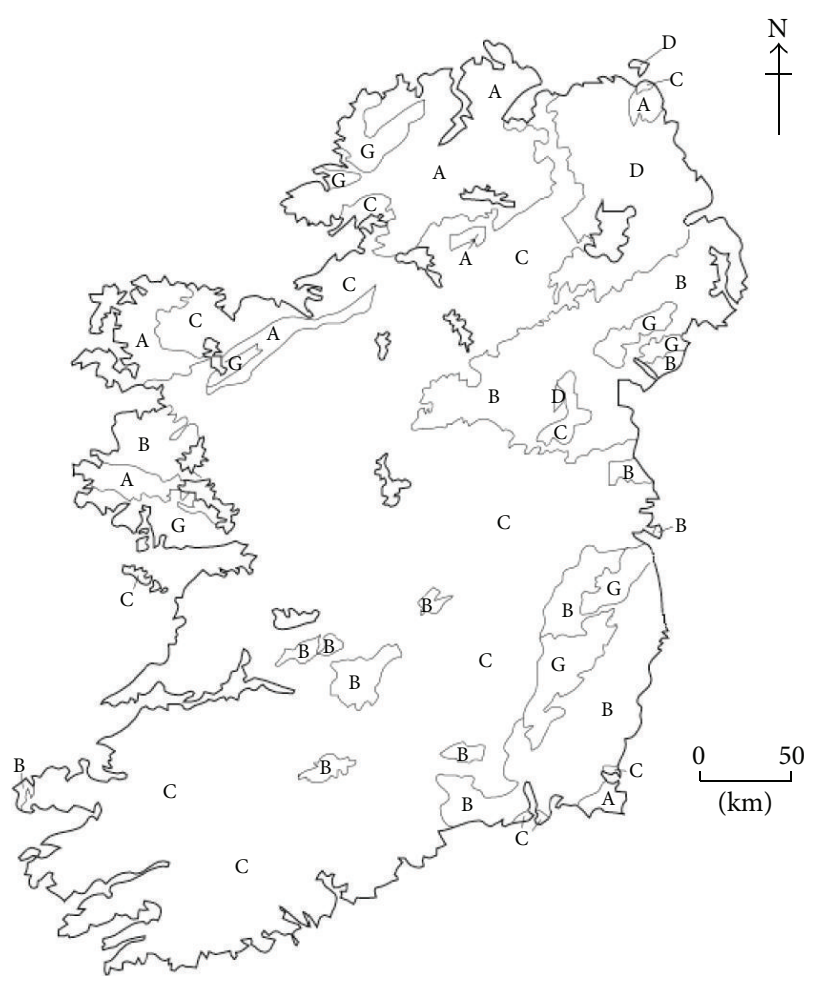

FIGURE 2: Rock types in Ireland and the era in which they were formed. A: Precambrian; B: lower Palaeozoic; C: upper Palaeozoic (includes schist); D: Mesozoic and Tertiary; G: granite [11].

grid and surrounding road infrastructure; adherence with protective European legislation (i.e., presence of protected areas); and the presence of existing wind farms.

\section{Results and Discussion}

Six sites were identified using the OSI Map Viewer which met the preliminary requirements for a wind-PHES development; the locations of these sites are highlighted in Figure 3. As outlined previously, at each of the marine sites the Atlantic Ocean was modelled as the lower reservoir for PHES. There were no preexisting facilities at any of the identified marine sites which could act as an upper reservoir; thus in each case the excavation of an upper reservoir would be necessary. At one of the identified freshwater sites there is an existing lake which could act as upper reservoir for a wind-PHES facility; the excavation of a lower reservoir would be necessary at this site. Existing lakes were modelled as potential upper and lower reservoirs at the two remaining freshwater sites identified. There are no wind farms at any of the investigated sites at present: preexisting wind farms are not an essential criterion for the development of a combined wind-PHES facility but would reduce the financial investment associated with such a development. 


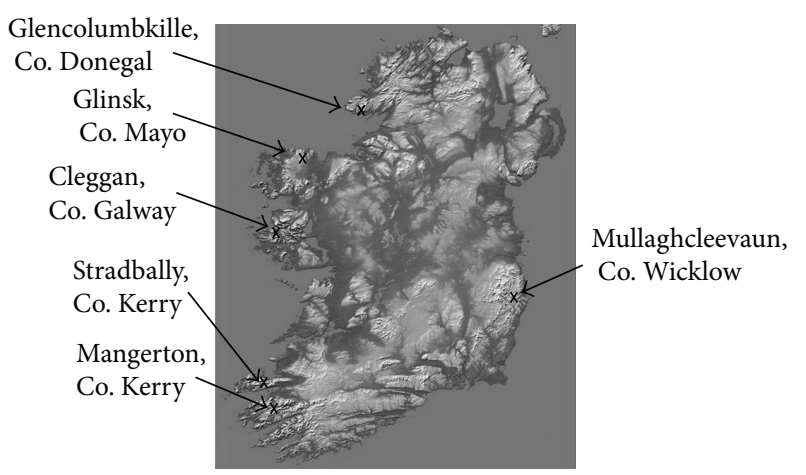

FIGURE 3: Relative location of each potential wind-PHES site (after NASA [13]).

\subsection{Marine Sites}

3.1.1. Glencolumbkille, Co. Donegal. Glencolumbkille, located in the northwest of Ireland (Figure 3), experiences wind speeds of $10.75-11.00 \mathrm{~ms}^{-1}$ at the highest peaks in this location. These wind speeds represent a good wind resource; however this wind speed drops to $8.50-8.75 \mathrm{~ms}^{-1}$ within a relatively short distance [9]. The lower wind speeds may have implications for the specific location of a renewable energy development in this area but remain viable for electricity generation from wind energy.

There are a number of coastal mountains underlain predominantly by schist [14] in the area surrounding Glencolumbkille which have a reasonable incline. Mullyoo Mountain, for example, has a maximum elevation of $219 \mathrm{~m}$; however it is located approximately $1 \mathrm{~km}$ from the coast which reduces the head flow rate and which would increase the costs associated with transferring water between an upper reservoir and the Atlantic Ocean. A second mountain peak, Malin More, is located closer to the coast and would therefore have lower associated costs. Although the peak of Malin More (131 m) is below the ideal head height of $200 \mathrm{~m}$ modelled in this study it is within the range recommended by Lacal Arántegui et al. [12] and is therefore a viable option for a combined wind-PHES development according to the wind speed and topographical criteria.

Planned upgrades to the transmission network, which are to be completed by 2025 [15], will upgrade the network at Binbane Station which is located $19.60 \mathrm{~km}$ from Glencolumbkille. In addition, there are a number of existing roads in the vicinity of the suggested sites at Glencolumbkille which would facilitate access and reduce the capital costs associated with construction at either of these sites. The potential of these sites for a combined wind-PHES development, however, is superseded by the presence of both a special area of conservation (SAC) and a special protection area (SPA) in this area [9] which ultimately makes these sites unavailable unless a mitigation measure of some sort can be established for this area with the combined agendas of energy generation and habitat and species protection.
3.1.2. Glinsk, Co. Mayo. Glinsk, also located in the northwest of Ireland (Figure 3), is also underlain by schist [14]; the site lies in a U-shaped valley with a natural incline from the Atlantic Ocean to the mountain crest. County Mayo experiences the highest mean wind speeds in the country and at $100 \mathrm{~m}$ height the mean wind speed at Glinsk is 12.00$12.25 \mathrm{~ms}^{-1}$ [9]. The peak of Glinsk Mountain is $304 \mathrm{~m}$ which satisfies the modelled head height criterion for PHES and the seashore is a short distance from the peak which would impart a strong head when water is released from an upper reservoir.

The region is serviced by both national and primary roads and a minor road leads to the identified site itself. The peak of the mountain is approximately $1 \mathrm{~km}$ from the existing road which could contribute significant financial savings during construction of the facility. Glinsk is not currently connected to the electricity transmission grid; however planned updates to the grid will strengthen the transmission network approximately $20 \mathrm{~km}$ to the south of the site. Although an SPA is located approximately $1 \mathrm{~km}$ away from the peak, the site of interest is not contained within an area of conservation or protection [9]. Taking each of these characteristics into consideration, Glinsk is therefore considered a potentially suitable site for a combined windPHES development.

3.1.3. Cleggan, Co. Galway. Located on the western coast of Ireland (Figure 3), Cleggan has a strong wind resource measuring $11.25-11.50 \mathrm{~ms}^{-1}$ at its peak [9]. This wind resource remains high in all surrounding areas; thus wind turbines could be constructed below the peak to reduce the impact on the local scenery without losing electricity generation potential from wind. Cleggan is underlain with schist [14] and although there is an intrusion of quartzite in the area its presence is not considered to be a hindrance to the development of a wind-PHES facility due to its naturally resistant qualities [11].

There are no protected habitats in the area which would affect the location of a wind-PHES development [9]; however at just $146 \mathrm{~m}$ the highest peak in the Cleggan area is below the modelled head height but is within the range recommended by Lacal Arántegui et al. [12]. The closest existing road to the Cleggan site is located almost $3 \mathrm{~km}$ away. In addition, the closest transmission lines after the planned upgrade to the network is completed will be located more than $40 \mathrm{~km}$ away from the Cleggan site. Overcoming these infrastructural challenges would require a significant financial investment. Despite these factors, Cleggan is considered to be a potentially suitable site for a wind-PHES development.

\subsection{Freshwater Sites}

3.2.1. Stradbally Mountain, Co. Kerry. Stradbally Mountain, with a peak of $798 \mathrm{~m}$, has an excellent wind resource potential of $12.75-13.00 \mathrm{~ms}^{-1}$ [9]. This resource remains strong with declining elevation, meaning wind turbines could be constructed at a lower elevation to reduce the impact on local 
scenery without sacrificing wind potential. The underlying bedrock at Stradbally Mountain consists of sandstone, siltstone, and mudstone which are not ideal for the storage of water for a PHES facility. There are existing lakes on the mountain, however, which could potentially be used as upper and lower reservoirs: the upper lake is located at a height of $616 \mathrm{~m}$ and the lower lake is located at a height of $209 \mathrm{~m}$ which would impart a sufficient head for PHES. The $1.7 \mathrm{~km}$ distance between the lakes, however, is substantial. In addition, there is an area of elevated land between the two lakes which would require an underground pipeline to be laid to facilitate the movement of water between the two reservoirs.

The closest access point to the electricity transmission grid is over $25 \mathrm{~km}$ away and the closest access point to the road network is approximately $2.5 \mathrm{~km}$ from the site. Although Stradbally Mountain has an excellent wind resource and the presence of existing lakes would avoid the financial and physical burden of excavating artificial reservoirs, substantial capital investment would be required to make Stradbally Mountain a viable site for renewable electricity generation. Furthermore, Stradbally Mountain is located in the middle of a SAC [9] which renders this site unavailable for development of a wind-PHES facility unless a compromise can be found which facilitates both renewable energy generation and species protection.

3.2.2. Mangerton Mountain, Co. Kerry. Mangerton Mountain, at $843 \mathrm{~m}$ elevation, experiences a wind resource of 12.50 $12.75 \mathrm{~ms}^{-1}$ [9]; this wind resource remains strong with declining elevation and as such wind turbines could be constructed at lower elevations without reducing energy potential. As with Stradbally Mountain, Mangerton Mountain is not underlain by schist and therefore lacks the impermeable bedrock present in some of the other sites considered in this study. There are two existing lakes located on the mountain which could act as upper and lower reservoirs: the upper lake is located at a height of $670 \mathrm{~m}$ and the lower lake at a height of $428 \mathrm{~m}$ which would provide a suitable head for PHES; however the distance between the lakes is substantial at almost $800 \mathrm{~m}$.

Although there is an extensive road network in the vicinity of Mangerton Mountain, the closest access point to this road network is almost $5 \mathrm{~km}$ from the proposed site; obtaining access to the site would therefore require substantial financial investment. In terms of transmission, this site is located approximately $7.75 \mathrm{~km}$ from the nearest grid lines; thus connection costs would be considerably less than at other sites though they must still be considered. Despite having a number of positive attributes for development of a wind-PHES facility, as with Stradbally Mountain, Mangerton Mountain is located in an area identified for protection under European legislation [9] which ultimately means this site is unavailable for an energy development unless a compromise can be found which facilitates renewable energy generation and species and habitat protection.
3.2.3. Mullaghcleevaun, Co. Wicklow. Mullaghcleevaun has excellent wind conditions with mean wind speeds of $12.50-$ $12.75 \mathrm{~ms}^{-1}$ at the peak of the mountain (849 m elevation). This wind resource remains strong with declining elevation: at $600 \mathrm{~m}$ above sea level the mean wind speed is 10.00 $10.25 \mathrm{~ms}^{-1}$ [9]. Cleevaun Lough, a naturally occurring lake, is located $700 \mathrm{~m}$ above sea level and could be used as an upper reservoir for a combined wind-PHES development. Wind turbines could be sited at this location or at a lower elevation to reduce the impact on the local scenery while maximising the wind resource potential. Excavation of a lower reservoir would be required if this site was to be used for combined wind-PHES electricity generation, and the natural topography of the land means that a lower reservoir could be located in close proximity to the upper reservoir while maintaining a sufficient head for PHES.

From an infrastructure point of view, an existing road network is located approximately $4 \mathrm{~km}$ from the identified site. After upgrading the transmission network the closest transmission link will be approximately $6.75 \mathrm{~km}$ from the site which makes Mullaghcleevaun one of the more networkaccessible sites under investigation. As in the case of the other freshwater sites identified, the biggest obstacle to the development of a wind-PHES electricity generation project at Mullaghcleevaun is the presence of a SAC [9]. This hurdle, as in the former cases, can only be overcome if a compromise can be found which allows the implementation of renewable electricity generation in Ireland while ensuring protection of species and habitats identified by European legislation.

Table 1 summarises the suitability of each site for the development of a combined wind-PHES project according to the criteria used in this study to determine feasibility. From this table it is evident that Glinsk, Co. Mayo is the preferred site for development of a wind-PHES facility. Cleggan, Co. Galway is ranked second as it is not located within an area protected under EU legislation. Although it does not satisfy the $200 \mathrm{~m}$ elevation criterion applied in this study, it is within the range proposed by Lacal Arántegui et al. [12] for PHES development. Each of the freshwater sites investigated was eliminated due to the presence of an area protected under either the EU Birds Directive or the EU Habitats Directive. None of the sites fulfilled the recommended criterion of the presence of a preexisting wind farm. While this is not an essential factor in such a development, it would impart significant financial savings during the construction of a wind-PHES facility.

Table 1 also lists the potential score achievable by each site if a suitable compromise could be found between European legislation which requires species and habitat protection and European legislation which requires renewable energy generation in member states. This revised scoring raises the ranking of Glencolumbkille, Co. Donegal as a potential site for a combined wind-PHES facility to joint first with Glinsk, Co. Mayo. Mullaghcleevaun, Co. Wicklow remains the highest ranked freshwater site under these revised scores due to the presence of suitable bedrock for water storage, a criterion which is not met by either of the other freshwater sites identified. 
TABLE 1: Suitability of each site investigated for development of a wind-PHES electricity generation facility.

\begin{tabular}{|c|c|c|c|c|c|c|}
\hline Site & $\begin{array}{c}\text { Glencolumbkille, } \\
\text { Co. Donegal }\end{array}$ & $\begin{array}{c}\text { Glinsk, } \\
\text { Co. Mayo }\end{array}$ & $\begin{array}{l}\text { Cleggan, } \\
\text { Co. Galway } \\
\end{array}$ & $\begin{array}{l}\text { Stradbally, } \\
\text { Co. Kerry }\end{array}$ & $\begin{array}{c}\text { Mangerton, } \\
\text { Co. Kerry }\end{array}$ & $\begin{array}{c}\text { Mullaghcleevaun, } \\
\text { Co. Wicklow }\end{array}$ \\
\hline Wind speed $\left(\mathrm{ms}^{-1}\right)$ & $r$ & $\checkmark$ & $\checkmark$ & $\checkmark$ & $r$ & $r$ \\
\hline Elevation $(>200 \mathrm{~m})$ & $\checkmark$ & $\checkmark$ & $x$ & $\checkmark$ & $\checkmark$ & $\checkmark$ \\
\hline Geology (impermeable bedrock) & $\checkmark$ & $\checkmark$ & $\checkmark$ & $\times$ & $x$ & $\checkmark$ \\
\hline Grid connection (<20 km distant $)$ & $\checkmark$ & $\checkmark$ & $x$ & $x$ & $\checkmark$ & $\checkmark$ \\
\hline Road infrastructure ( $<1.5 \mathrm{~km}$ distant $)$ & $\checkmark$ & $\checkmark$ & $x$ & $x$ & $x$ & $x$ \\
\hline No $S A C^{a}$ present & $\times$ & $\checkmark$ & $\checkmark$ & $x$ & $x$ & $\times$ \\
\hline No SPA ${ }^{a}$ present & $\times$ & $\checkmark$ & $\checkmark$ & $\times$ & $\times$ & $\times$ \\
\hline Existing wind farm present & $\times$ & $x$ & $x$ & $\times$ & $x$ & $x$ \\
\hline Total $^{\mathrm{b}}$ & $5(7)^{\mathrm{c}}$ & 7 & 4 & $2(4)$ & $3(5)$ & $4(6)$ \\
\hline
\end{tabular}

SAC: special area of conservation (per Directive 94/43/EEC); SPA: special protection area (per Directive 79/409/EEC).

${ }^{\mathrm{b}}$ Out of 8 .

${ }^{\mathrm{c}}$ Possible score if a compromise on protective European legislation could be made.

\section{Conclusion}

A number of site criteria were used to investigate the feasibility of the development of combined wind-PHES for renewable energy generation in Ireland. Under the criteria applied it was observed that there is limited potential for such development as only six sites fulfilled the preliminary requirements investigated. Of the sites investigated, Glinsk, Co. Mayo which is located in the northwest of the country proved to be the most suitable site as it fulfilled the criteria of mean wind speed, minimum elevation to provide sufficient head differential, underlying bedrock impermeability, and the absence of protected areas. Although Cleggan, Co. Galway did not satisfy the modelled elevation criterion, the elevation at the site is within a recommended range for PHES and as such, having satisfied the other essential criteria, is a potential second choice for development of a windPHES facility. The elimination of the remaining four potential sites due to the presence of areas protected under European legislation highlights the nonenergy related obstacles which stand in the way of renewable energy generation in Ireland. If a mitigation measure can be introduced which facilitates both renewable energy generation and species and habitat protection, additional sites become potentially available for electricity generation in Ireland from wind energy and pumped hydro energy storage. This would also facilitate decentralisation of energy generation throughout Ireland by increasing the total number of electricity generation facilities dispersed throughout the island.

\section{Conflict of Interests}

The authors declare that there is no conflict of interests regarding the publication of this paper.

\section{References}

[1] M. Howley and M. Holland, Energy in Ireland: Key Statistics 2013, Sustainable Energy Authority of Ireland, Dublin, Ireland, 2013.
[2] IWEA, Wind Energy Technology, Irish Wind Energy Association, Kildare, UK, 2013.

[3] C. Goodbody, E. Walsh, K. P. McDonnell, and P. Owende, "Regional integration of renewable energy systems in Irelandthe role of hybrid energy systems for small communities," International Journal of Electrical Power and Energy Systems, vol. 44, no. 1, pp. 713-720, 2013.

[4] Risø National Laboratory, European Wind Atlas, Roskilde, Denmark, Risø National Laboratory, 1989, http://www.windatlas. $\mathrm{dk} /$ europe/landmap.html.

[5] ESB, Turlough Hill \& Liffey Stations, ESB Electric Ireland, Dublin, Ireland, 2009.

[6] R. Bakis, "The current status and future opportunities of hydroelectricity," Energy Sources B: Economics, Planning and Policy, vol. 2, no. 3, pp. 259-266, 2007.

[7] W. H. Reuter, S. Fuss, J. Szolgayová, and M. Obersteiner, "Investment in wind power and pumped storage in a real options model," Renewable and Sustainable Energy Reviews, vol. 16, no. 4, pp. 2242-2248, 2012.

[8] S. Engström, T. Lyrner, M. Hassanzadeh, T. Stalin, and J. Johansson, Tall Towers for Large Wind Turbines: Report from Vindforsk Project V-342 Höga Torn För vindkraftverk, Vindforsk, Stockholm, Sweden, 2010.

[9] SEAI, SEAI Wind Atlas, Sustainable Energy Authority Ireland, Dublin, Ireland, 2013.

[10] J. P. Deane, B. P. Ó Gallachóir, and E. J. McKeogh, “Technoeconomic review of existing and new pumped hydro energy storage plant," Renewable and Sustainable Energy Reviews, vol. 14, no. 4, pp. 1293-1302, 2010.

[11] I. Sanders, Six Common Kinds of Rock from Ireland, Department of Geology, Trinity College Dublin, Dublin, Ireland, 2008.

[12] R. Lacal Arántegui, E. Tzimas, A. Bocin-Dumitriu, and A. Zubaryeva, SETIS Expert Workshop on the Assessment of the Potential of Pumped Hydropower Storage, SETIS, Petten, The Netherlands, 2012.

[13] NASA, Topography of Ireland, NASA Earth Observatory, Goddard Space Flight Centre, Greenbelt, Md, USA, 2005.

[14] GSI, "Bedrock geology of Ireland," Geological Survey of Ireland, Dublin, Ireland, 2004.

[15] Eirgrid, Grid 25: A Strategy for the Development of Ireland's Electricity Grid for a Sustainable and Competitive Future, Eirgrid, Dublin, Ireland, 2009. 


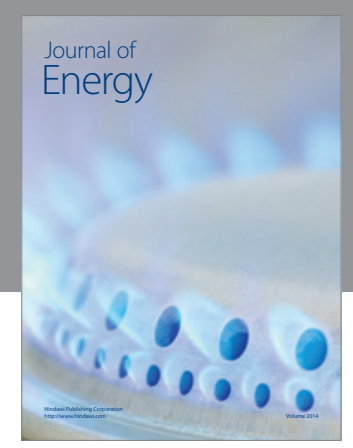

Journal of

Industrial Engineering
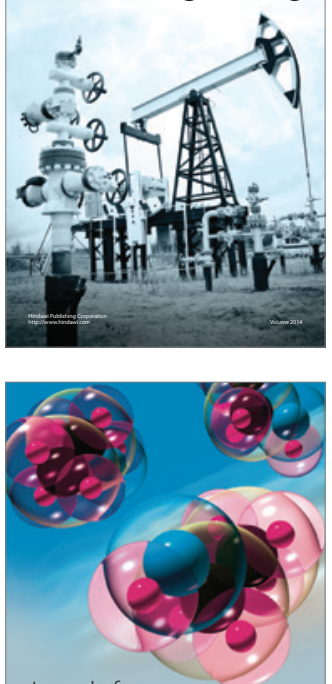

Fuels
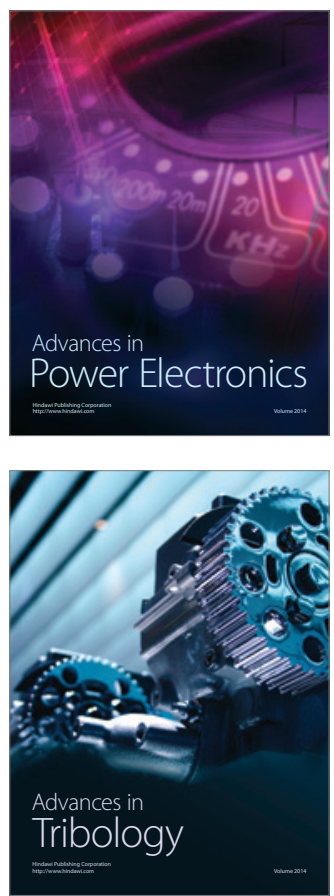

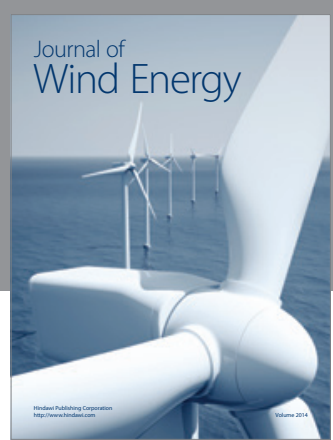

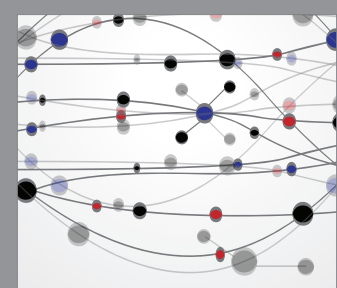

The Scientific World Journal

Submit your manuscripts at http://www.hindawi.com

Journal of

Structures
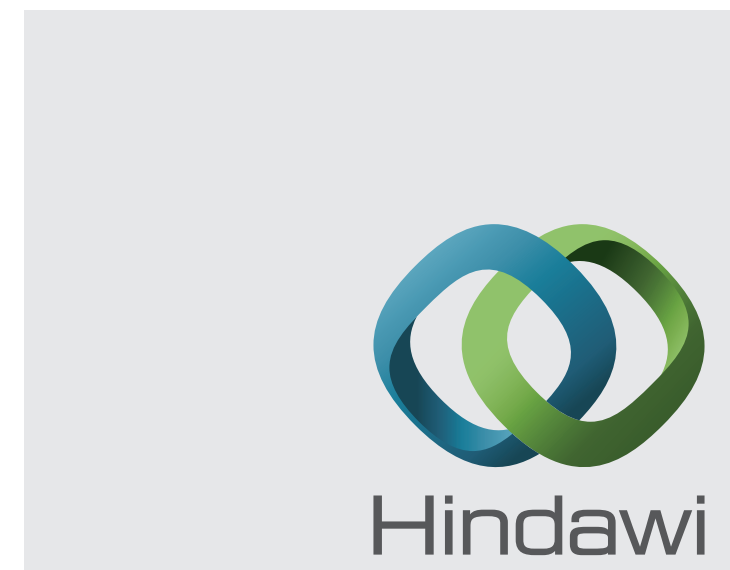

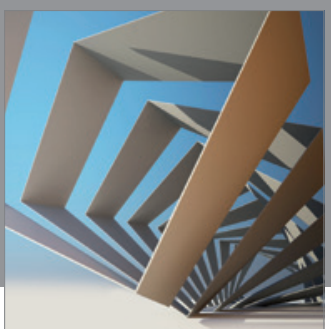

Rotating

Machinery
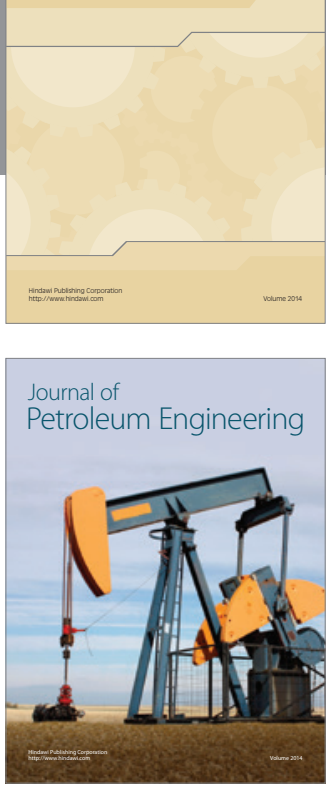

Journal of

Solar Energy
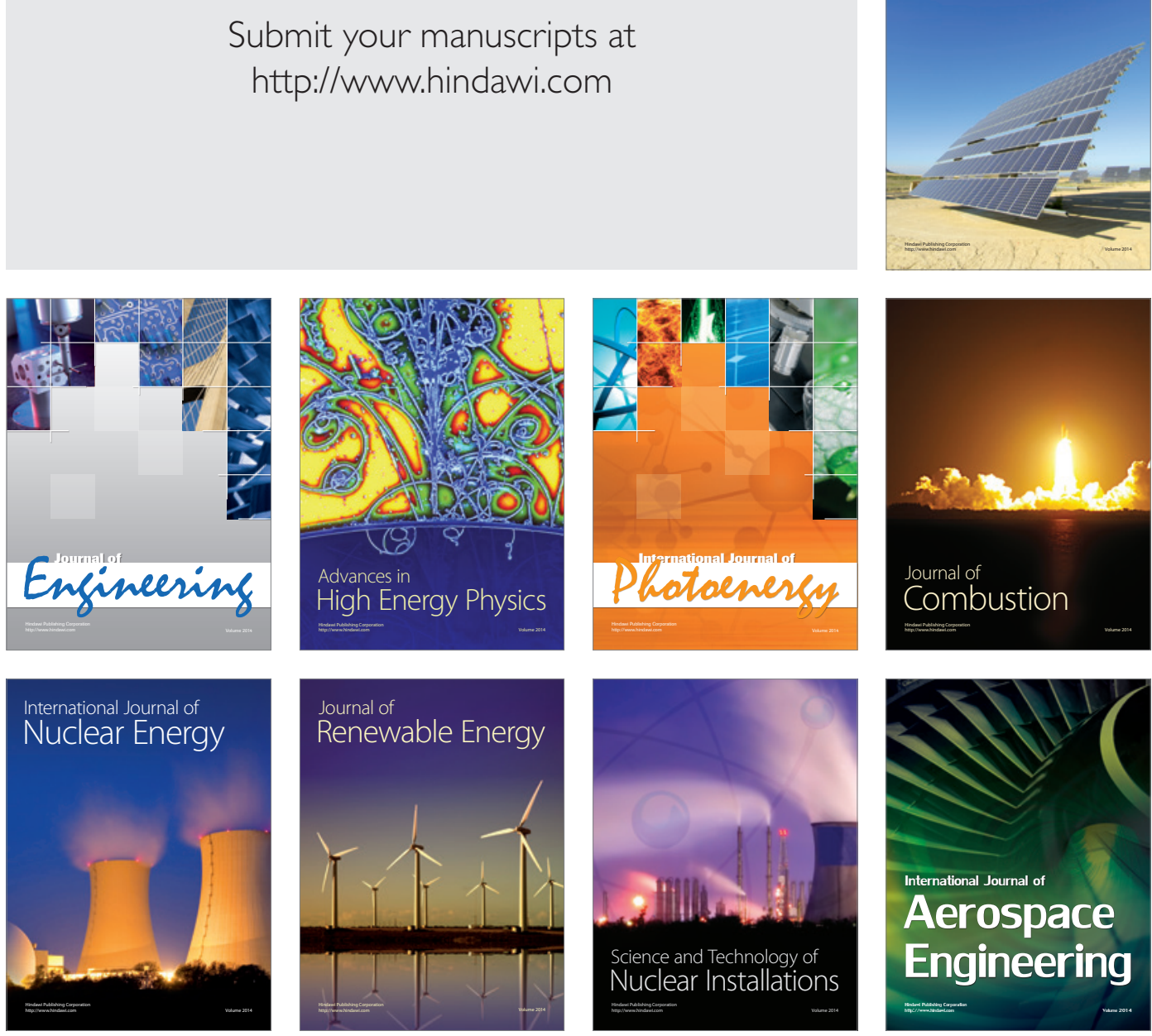